\title{
Does the New Rural Cooperative Medical System with higher reimbursement rates reduce catastrophic health expenditures in rural China?
}

\author{
Zaiyu Chen ${ }^{1}$, DaiJun Zhao ${ }^{2}$, Peter C. Coyte*3 \\ ${ }^{1}$ Department of Economics, Business School, China Pharmaceutical University, Nanjing, Jiangsu Province, China \\ ${ }^{2}$ The Disease Control and Prevention Center of Hongkou District, Shanghai, China \\ ${ }^{3}$ Institute of Health Policy, Management and Evaluation, University of Toronto, Toronto, Ontario, Canada
}

Received: June 24, 2015

DOI: $10.5430 /$ ijh.v1n1p32

\author{
Accepted: August 10, 2015 \\ Online Published: August 14, 2015
}

URL: http://dx.doi.org/10.5430/ijh.v1n1p32

\begin{abstract}
We used recently available data from the China Health and Nutrition Survey (CHNS) from 2004 to 2011 to re-examine the impact of the New Rural Cooperative Medical System (NRCMS) in the People's Republic of China on exposure to catastrophic health expenditures. We found that the NRCMS with universal coverage and higher reimbursement rates in 2011 did not reduce the incidence and intensity of out-of-pocket catastrophic payments. Moreover, there were important distributional implications with the poorest protected to the least extent. As such, we suggest policymakers should consider using the NRCMS to shelter rural residents, especially the poorest, from catastrophic medical expenses.
\end{abstract}

Key Words: Catastrophic health care expenditures, China, New Rural Cooperative Medical System

\section{INTRODUCTION}

Out-of-pocket (OOP) payments are major sources of health care finance in low and middle-income countries and it may expose households to catastrophic health care expenditures. ${ }^{[1,2]}$ Catastrophic health care expenditures occur when health care expenditures exceed a household's ability to pay, and thereby, affect a household's standard of living. ${ }^{[2]}$ Consequently, exposure to such catastrophic health care expenditures has become an urgent public policy priority in many low- and middle-income countries, such as China. This situation offered the motivation for the introduction in 2003 of the New Rural Cooperative Medical System (NRCMS); however, knowledge about the effectiveness of the NCMS in reducing catastrophic health care expenditures for the rural residents is still limited.

From the beginning of the economic reforms in the 1980's to the end of twenty century, over $90 \%$ of rural residents in China were uninsured. To improve financial protection for health care for rural populations, the NRCMS was introduced in 2003. The NRCMS is a government-run voluntary health insurance program with substantial subsidies from central and local governments. The NRCMS was operated at the county level and was largely focused, in most localities, on the cost of inpatient care. ${ }^{[3]}$ There has been a rapid increase in this form of health insurance coverage in rural China since it was first introduced. Beginning with only 333 out of 2,862 rural counties in 2004, the NRCMS have expanded to cover

\footnotetext{
${ }^{*}$ Correspondence: Peter C. Coyte; Email: peter.coyte@ utoronto.ca; Address: Health Sciences Building, Suite 425, 155 College Street, Toronto, ON, M5T3M6, Canada.
} 
all counties by the end of 2009 (China statistical yearbook, 2013). Moreover, while premiums for the NRCMS remained low for rural residents in China, they have increased six-fold from 2004, when they were 50 RMB per beneficiary, to 308 RMB in 2012 (China statistical yearbook, 2013).

The purpose of this paper is to measure the impact of the NRCMS on catastrophic health care expenditures in rural China. Most of the previous studies on financial protection associated with the NRCMS relied on data generated during the early phase of the system and was not nationally representative. ${ }^{[4,5]}$ The key finding from this literature was that the NRCMS did not reduce the incidence of catastrophic health care expenditures due to the low reimbursement arrangement associated with the NRCMS. However, there were important changes to the NRCMS in recent years, and therefore, it would be timely to re-assess the impact of the NRCMS for the whole country. For example, the NRCMS coverage rate in rural China was universal since 2009, and both premiums and reimbursement rates have subsequently increased. On the other hand, most previous studies used descriptive and arithmetic methods to measure the effect of the NRCMS on the occurrence of catastrophic expenditures, and consequently, these studies were subject to potential confounding. In this paper, we adopted a probit model and recently available data from the nationally representative China Health and Nutrition Survey (CHNS) from 2004 to 2011 to re-assess the impact of rural health insurance system on catastrophic health care expenditures.

In prior research in this area, the issue was how to define an expenditure threshold for households facing catastrophic health care spending. In most cases, catastrophic spending was considered to exist if the share of income devoted to OOP health care expenditures exceeded a fixed proportion of household income. ${ }^{[2,6]}$ Rama Joglekar ${ }^{[7]}$ used different thresholds for catastrophic health care expenditures for the rich when compared to that for the poor. A threshold of zero percent was set for poor households when income was below the poverty line and a threshold greater than zero was set for other households. These investigators argued that any spending on health care was a catastrophic payment for poor households below the poverty line. In contrast, we adopted a different standard. Specifically, we defined an absolute amount for OOP health care expenditures for households whose incomes are below the median income and a fixed proportion of income allocated to OOP expenditures for other households. We argue that it was unconvincing, even for household's with incomes below the poverty line, to suggest that even a small level of OOP health care spending could be catastrophic, and as a result we propose a more general definition.
The structure of the paper is as follows. In Section 2, we summarize literature concerning catastrophic health care expenditures and health insurance. Data and methods used to estimate the impact of the NRCMS on catastrophic health care expenditures in China are outlined in Section 3. Empirical results are reported in Section 4, and a tentative conclusion and discussion of our findings are reported in Section 5.

\section{LITERATURE REVIEW ON CATASTROPHIC HEALTH CARE EXPENDITURES}

In studies dealing with catastrophic health care expenditures, the first research question concerns the setting of the threshold used to define financial exposure. This threshold was often set as proportion of household income or expenditures assigned to medical expenditures. Wagstaff and Doorslaer ${ }^{[6]}$ and Doorslaer et al. ${ }^{[1]}$ set thresholds of $2.5 \%, 5 \%, 10 \%$ and $15 \%$ of pre-payment total disposable income, and $10 \%, 20 \%$, $30 \%$ and $40 \%$ of the capacity to pay which was defined as pre-payment income less actual food spending. They argued that a household's capacity to pay should be defined as the amount of effective income remaining after basic subsistence needs had been met. These studies adopted a relative approach to the estimation of catastrophic health care expenditures. To supplement counting the number of households who overshoot thresholds, Wagstaff ${ }^{[8]}$ suggested using a catastrophic payment gap, defined as the average amount by which OOP spending exceeded the threshold.

Compared with taking a fixed proportion of income as the threshold in the relative approach, different threshold values were set for the rich and the poor. Joglekar ${ }^{[7]}$ and Pal ${ }^{[9]}$ set a threshold of zero percent for households whose incomes were below the poverty line and a threshold as a fixed proportion of income for other households. They argued that any spending on health care was a catastrophic payment for the very poor. However, this approach was not convincing as it would define catastrophic expenditures to situations in which very poor households incurred any health expenditures. For these households, it is their very low level of income that moves these economically vulnerable households into poverty, rather than health care expenditures.

OOP payments were the main source of finance for health care in low-income countries. ${ }^{[10]}$ This form of finance has important consequences for the way in which households may face the risk of catastrophic medical expenses. A vast literature has estimated the impact of OOP on the incidence of catastrophic health care expenditures in low income countries..$^{[1,11-13]}$ In China, Kyrgyzstan, and Vietnam, catastrophic payments were more likely to occur than in any other 
Asian country because the poor were not exempt from medical charges, and consequently, they had to pay more by OOP than elsewhere. ${ }^{[1]} \mathrm{Xu}$ et al. ${ }^{[2]}$ used data from household surveys in 59 countries and found that few households would be affected by catastrophic payments if OOP health expenditures were reduced to levels lower than $15 \%$ of total health expenditures. Xu et al. ${ }^{[2]}$ argued that the problem of catastrophic health expenditure would not be addressed by simply raising household income; mechanisms for financial risk pooling must be effectively developed in many countries.

The impact of social health insurance on catastrophic health care expenditures in low-income countries has been addressed in the international literature. Sepehri et al. ${ }^{[14]}$ found social insurance had a negative and significant impact on OOP health expenditure in Vietnam. Cavagnero et al. ${ }^{[15]}$ also found medical insurance reduced the probability of catastrophic OOP health payments in Argentina. In India, there was limited health insurance coverage and the probability of catastrophic OOP expenditures fell by 10 percent if the head of the household had medical insurance. ${ }^{[7]}$ As a consequence, increased access to insurance coverage may help protect households from catastrophic health expenditures.

The incidence of catastrophic health expenditures depends on the underlying reimbursement rates embodied in social health insurance. If reimbursement rates are low, resulting in larger OOP payments by patients, then social health insurance may have a limited impact on the incidence of catastrophic health expenditures. Hongmei Yi, et al. ${ }^{[5]}$ examined the impact of the NRCMS on catastrophic expenditures, using survey data for 2004 and 2007 for rural China. They defined a fixed threshold of 4,000 RMB (In 2013, \$1US = 6.10 RMB) of medical expenditures and found that low reimbursement rates inherent in the NRCMS meant that it did not provide sufficient financial protection to the rural population. Yip and $\mathrm{Hsiao}^{[4]}$ found the NRCMS in the Western and Central regions of China didn't protect the population from medical-induced impoverishment. There were high OOP payments for the NRCMS so that its role for financial protection was limited in 2006. Moreover, much of the early literature found that the NRCMS increased the use of medical services and thereby actually increased total OOP payments for patients. ${ }^{[3,16,17]}$

To summarize, there were considerable controversy concerning the threshold used to define catastrophic health care expenditures. While many studies that have assessed the impact of the NRCMS on catastrophic health care expenditures, most of those studies relied on early data or small-scale health surveys that were difficult to generalize. Specifically, during the initial period when the NRCMS was introduced both its coverage of the population and the levels of reimbursement for health expenditures were low. It is therefore important to use new and more generalizable data to reestimate the impact of the NRCMS, as the coverage rate and premiums have increased dramatically in recent years. By this way, we can find how to design social medical insurance to protect households from catastrophic heath expenditures.

\section{DATA AND METHODS}

The data used in our analysis was from the CHNS, a nationally representative household survey conducted by the Carolina Population Center at the University of North Carolina at Chapel Hill and the National Institute of Nutrition and Food Safety at the Chinese Center for Disease Control and Prevention. The CHNS data covers nine provinces, including Eastern and mid-west areas of China, which vary substantially in terms of geography, economic development, public resources, and health indicators. With data sets covering four counties in each surveyed province, this sample comprised a total of 36 counties. The first round of the CHNS survey was conducted in 1989. There were nine panels in the survey with the last wave conducted in 2011. The survey provided comprehensive information on household's income, health status, medical expenditures and health insurance. Four recent rounds of data for 2004, 2006, 2009 and 2011 were used in this study.

While we adopted many of the same methods used by other researchers that have tried to estimate the incidence of catastrophic health care expenditures, our main departure was in the use of a fixed absolute threshold for poor households and a fixed proportional threshold (i.e. 25\%) of per capita household income for other households.

We divided the whole sample into five quintiles according to household income ranking. In rural China, households in the two lowest quintiles are deemed to be poor as their average annual household income per capita were just 2,000 RMB and 4,255 RMB in 2011 (China statistical yearbook, 2013). In view of this situation, catastrophic expenditure thresholds for households in the two lowest quintiles, i.e. quintiles 1 and 2, were defined as a fixed absolute amount. This fixed amount was defined as the amount of medical expenditures used to define catastrophic expenditures for the lowest income household in quintile 3 . For other households, the threshold was set as a fixed proportion (specifically, 25\%) of household income. Household income and medical expenditures were defined on a per capita basis. For households in quintiles 1 and 2 , let $\mathrm{T}_{i}$ be the medical payments of household $\mathrm{i}, \mathrm{z}_{1}$ be the fixed absolute threshold, Ei be an indicator for catastrophic expenditure which is equal to 1 if $\mathrm{T}_{i}>\mathrm{z}_{1}$ and zero otherwise. For those households in other quintiles, $\mathrm{y}_{i}$ 
represents household income, $\mathrm{z}_{2}$ is the proportional threshold of household income used to define catastrophic expenditures and $\mathrm{E}_{i}$ is equal to 1 if $\mathrm{T}_{i} / \mathrm{y}_{i}>\mathrm{z}_{2}$ and zero otherwise. Then, we measured the two indicators of catastrophic payments as:

(1) Average number of households that incur catastrophic payments, which capture the incidence of catastrophic expenditures:

$$
H_{c a t}=\frac{1}{n} \sum_{i=1}^{n} E_{i}
$$

where $\mathrm{H}_{\text {cat }}$ is headcount; $\mathrm{n}$ is the sample size.

(2) Average gap in the share of excess expenditures for catastrophic payments. This captures the intensity of catastrophic payments in excess of the threshold for those whose household's income share on medical expenditures is above the threshold.

$$
G_{\text {cat }}=\sum_{i=1}^{n} O_{i} / \sum_{i=1}^{n} E_{i}
$$

where $\mathrm{G}_{\text {cat }}$ is the share of income associated with payments in excess of the threshold averaged for households incurring catastrophic payments. It is the average gap in the share of catastrophic payments in income. $\mathrm{O}_{i}$ is the share of income associated with catastrophic overshoots, for those households in quintile 1 and $2, \mathrm{O}_{i}=\left(\mathrm{T}_{i}-\mathrm{z}_{1}\right) / \mathrm{y}_{i}$, if $\mathrm{T}_{i} / \mathrm{y}_{i}>\mathrm{z}_{1} / \mathrm{y}_{i}$ and zero otherwise. For those households in other quintiles, $\mathrm{O}_{i}=$ $\mathrm{T}_{i} / \mathrm{y}_{i}-\mathrm{z}_{2}$, if $\mathrm{T}_{i} / \mathrm{y}_{i}>\mathrm{z}_{2}$ and zero otherwise.

In previous studies, the catastrophic expenditure threshold varied from $2.5 \%$ to $25 \%$ of pre-payment per capita household's income or was set as $40 \%$ of the capacity to pay. ${ }^{[1]}$ In our study, we set the threshold at $25 \%$ of per capita household's income. This threshold value is close to $40 \%$ of the capacity to pay threshold when the Engel's coefficient is 0.4. Usually, that fraction of the household's budget on health care is considered as the limit beyond which further expenditures on health care would deprive the household of necessary consumption. ${ }^{[2]}$

After measuring catastrophic health expenditures of residents, we were interested in finding out the determinants of such catastrophic heath expenditures. The probability of incurring catastrophic health expenditures (CHE) was modeled using a probit model. Determinants were hypothesizes to include economic and demographic variables, such as age, gender, education, household's income, health and health insurance. ${ }^{[9]}$ Apart from health insurance, our key explanatory variable, we also expected income and health variables to influence the occurrence of catastrophic health expenditures. Moreover, to verify the hypothesis that the NRCMS

Published by Sciedu Press offered protection to the poor from catastrophic payments, we considered a specific econometric model with an interaction term between NRCMS and a household's income. A significant negative estimated coefficient on the interaction term provides evidence to suggest that an increase in household income in the presence of the NRCMS lowers the occurrence of catastrophic payments, thereby affording greater protection to higher income households than to lower income households.

The presence of adverse selection presents a challenge in estimating the Probit model. Health coverage was not universal in 2004 and 2006. As a result, unhealthy people would like to participate in NRCMS in these two years. If this was the case then the NRCMS might be an endogenous variable, thereby potentially yielding biased estimates. For this reason, we first estimated the probit model with two-stage instrumental variable (IV) estimation using the participation rate of the NRCMS in a community as the IV for NRCMS. Then, we used a Wald test of exogeneity to examine if the NRCMS variable was endogenous. If not, we still used the probit regression model to derive coefficient estimates.

Definition and descriptive statistics for the variables used in the empirical analysis were shown in Table 1 . Those with age under 18 and with per capita household income under zero were excluded in our sample. There were 18,378 observations in our sample. Average incidence rate of catastrophic health expenditure was $0.87 \%$.

As shown in Table 2, we found NRCMS had a dramatic effect on insurance coverage in China. Since 2009, there has been almost universal health coverage in rural China, while coverage rate in 2004 and 2006 was only $12.27 \%, 47.08 \%$, respectively. Furthermore, the average reimbursement rate for the NRCMS was highest in 2011, which was $37.50 \%$ calculated within the sub-sample observations. In contrast, the figure for 2004 was just $3.59 \%$.

\section{Results}

\subsection{Measure of catastrophic health expenditure}

In order to measure the contribution of the NRCMS to the reduction in catastrophic health care expenditures, we compared expenditures under pre- and post-reimbursement of NRCMS. Indicators under the pre-reimbursement approach measured catastrophic health expenditure based on total medical expenditures. In contrast, indicators under the postreimbursement approach measured these indicators based on OOP payments excluding reimbursement from the NRCMS. Table 3 presented indicators of catastrophic medical expenditures for both pre-and post-reimbursement of NRCMS. From 2004 to 2011, there was not a significant difference 
in the incidence $\left(\mathrm{H}_{c a t}\right)$ of post-reimbursement catastrophic years. It indicated that total medical expenditure may imhealth expenditure. The pre- and post-reimbursement difference for Hcat were the same in 2004 and changed a little in 2006 and 2009, but it was bigger in 2011 than other years, with Hcat falling by $44 \%$ from post- to pre-reimbursement. It was because the incidence of pre-reimbursement catastrophic payments of NRCMS was higher in 2011 than other prove due to NRCMS in 2011 with higher reimbursement rates and NRCMS, even in 2011, may not reduce incidence of OOP catastrophic payments. Moreover, Table 3 showed NRCMS also did not reduce payments in excess of the threshold, which were paid by households incurring catastrophic medical expenses.

Table 1. Variable definition and the table data descriptive statistics

\begin{tabular}{llllll}
\hline Variables & Definition & Mean & SD & Min & Max \\
\hline CHE & Dummy variable, one for person incurring catastrophic health expenditure & 0.0087 & 0.093 & 0 & 1 \\
& in last four weeks before survey, defined by formula (1). & 59.23 & 41.56 & 0 & 100 \\
Part & NRCMS participation rate of community (\%). & 59.23 & 49.14 & 0 & 1 \\
NRCMS & Dummy variable, one for person with NRCMS. & 49.09 & 14.88 & 18 & 99 \\
Age & Age (year) & 0.48 & 0.50 & 0 & 1 \\
Gender & Dummy variable, one for male. & 0.85 & 0.35 & 0 & 1 \\
Marri & Dummy variable, one for married. & & & \\
& Education, illiteracy with 0 year, primary school with 6 years, junior high & & & \\
Edu & school with 9 years, senior high school with 12 years, university or collage & 6.01 & 4.25 & 0 & 19 \\
& with 16 years, graduate with 19 years. & & & \\
Income & Inflation-adjusted per capita household annual income (yuan, RMB). & $8,427.2$ & $11,385.6$ & 0.98 & $343,328.0$ \\
Hhsize & Household size. & 3.95 & 1.72 & 1 & 13 \\
Blood & Dummy variable, one for person with blood pressure. & 8.77 & 2.83 & 0 & 1 \\
Diabetes & Dummy variable, one for person with diabetes. & 1.11 & 10.48 & 0 & 1 \\
Myocard & Dummy variable, one for person with myocardial infarction. & 1.01 & 10.01 & 0 & 1 \\
Isch & Dummy variable, one for person with transient ischemic. & 0.50 & 7.06 & 0 & 1 \\
\hline
\end{tabular}

Table 2. Comparison of household income, health expenditures, NRCMS coverage and average reimbursement rate

\begin{tabular}{lllll}
\hline Item & $\mathbf{2 0 0 4}$ & $\mathbf{2 0 0 6}$ & $\mathbf{2 0 0 9}$ & $\mathbf{2 0 1 1}$ \\
\hline Population Coverage rate for the NRCMS (\%) & 12.27 & 47.08 & 88.96 & 91.02 \\
Per capita annual household income (RMB, yuan) & $5,350.4$ & $6,605.7$ & $10,158.0$ & $11,918.9$ \\
$\begin{array}{l}\text { Per capita OOP health expenditures in the last four weeks before survey (RMB, yuan), } \\
\text { calculation based on sub-sample }\end{array}$ & 642.03 & 584.96 & 639.14 & $1,055.83$ \\
OOP as a proportion of annual household income (\%) & 12.00 & 8.86 & 6.29 & 8.86 \\
$\begin{array}{l}\text { Average reimbursement rate from the NRCMS for all medical expenditures (\%), } \\
\text { calculation based on sub-sample. }\end{array}$ & 3.59 & 9.14 & 27.02 & 37.50 \\
$\begin{array}{l}\text { Sub-sample size (with positive health expenditure) } \\
\text { Full Sample size }\end{array}$ & 529 & 504 & 625 & 456 \\
\hline
\end{tabular}

Table 3. The incidence $\left(\mathrm{H}_{c a t}\right)$ and intensity $\left(\mathrm{G}_{c a t}\right)$ of catastrophic health expenditure

\begin{tabular}{lllllllll}
\hline \multirow{2}{*}{$\mathbf{Z}=\mathbf{2 5 \%}{ }^{*}$} & \multicolumn{3}{c}{ Pre-reimbursement of NRCMS } & \multicolumn{5}{c}{ Post-reimbursement of NRCMS } \\
\cline { 2 - 9 } & $\mathbf{2 0 0 4}$ & $\mathbf{2 0 0 6}$ & $\mathbf{2 0 0 9}$ & $\mathbf{2 0 1 1}$ & $\mathbf{2 0 0 4}$ & $\mathbf{2 0 0 6}$ & $\mathbf{2 0 0 9}$ & $\mathbf{2 0 1 1}$ \\
\hline Threshold for quintiles 1 \& 2 & 823.4 & 877.1 & $1,441.3$ & $1,729.0$ & 823.4 & 877.1 & $1,441.3$ & $1,729.0$ \\
$\mathrm{H}_{\text {cat }}(\%)$ & 1.04 & 0.86 & 1.0 & 1.50 & 1.04 & 0.82 & 0.78 & 0.84 \\
$\mathrm{G}_{\text {cat }}(\%)$ & 331.1 & 182.8 & 336.0 & 182.1 & 325.9 & 183.2 & 351.1 & 197.4 \\
\hline
\end{tabular}

Note. ${ }^{*}$ samples were divided into five quintiles by income. The threshold of quintile 1 and 2 was set as a fixed amount of heath expenditure. Specifically, this fixed amount was set as $25 \%$ of the household income for the lowest income household in quintile 3. 
Table 4 reported measures of catastrophic OOP health care expenditures stratified by per capita income quintiles. The poorest households experienced more catastrophic payments than the richest households across various years. $1.21 \%$ of households in quintile 1 exceeded the expenditure threshold of post-NRCMS reimbursement in 2011. By contrast, only $0.36 \%$ of richest households (quintile 5) exceeded these thresholds in that year. Intensity $\left(\mathrm{G}_{\text {cat }}\right)$ of catastrophic expenditure among the poorest households was still higher in 2011 than that for the richest set of households just as that in other years. These figures suggested that rural households with higher incomes were better protected financially from catastrophic payments in 2011 than households with the lowest incomes, while there was more extensive universal coverage and higher reimbursement rates of NRCMS in this year.

Table 4. Catastrophic health care expenditures by per capita income quintiles

\begin{tabular}{llllll}
\hline $\mathbf{Z}_{2}=\mathbf{2 5 \%}$ & & $\mathbf{2 0 0 4}$ & $\mathbf{2 0 0 6}$ & $\mathbf{2 0 0 9}$ & $\mathbf{2 0 1 1}$ \\
\hline \multirow{2}{*}{ Poorest } & $\mathrm{H}_{\text {cat }}(\%)$ & 1.06 & 0.97 & 0.92 & 1.21 \\
& $\mathrm{G}_{\text {cat }}(\%)$ & $1,233.18$ & 474.49 & $1,268.02$ & 494.82 \\
\multirow{2}{*}{ Quintile2 } & $\mathrm{H}_{\text {cat }}(\%)$ & 1.06 & 1.07 & 1.13 & 0.97 \\
& $\mathrm{G}_{\text {cat }}(\%)$ & 137.12 & 35.49 & 66.68 & 97.42 \\
Quintile3 & $\mathrm{H}_{\text {cat }}(\%)$ & 1.71 & 1.29 & 1.23 & 1.09 \\
& $\mathrm{G}_{\text {cat }}(\%)$ & 108.87 & 99.31 & 62.98 & 98.77 \\
\multirow{3}{*}{ Quintile4 } & $\mathrm{H}_{\text {cat }}(\%)$ & 0.85 & 0.54 & 0.61 & 0.60 \\
& $\mathrm{G}_{\text {cat }}(\%)$ & 38.68 & 198.79 & 73.34 & 40.79 \\
\multirow{2}{*}{ Richest } & $\mathrm{H}_{\text {cat }}(\%)$ & 0.53 & 0.22 & 0.00 & 0.36 \\
& $\mathrm{G}_{\text {cat }}(\%)$ & 42.46 & 74.44 & - & 30.02 \\
\hline
\end{tabular}

\subsection{Determinants of catastrophic health expenditure}

In Table 5, we presented the probit regression results for catastrophic OOP health expenditures. Model I was a probit regress with instrumental variables using the full sample from 2004 to 2011. However, a Wald test for exogeneity in model I indicated that NRCMS was not an endogenous variable. This finding may arise because participation in the NTCMS has to be based on the entire family rather than through individual selections, thereby reducing the occurrence of adverse selection. Model II was a probit regression model using the full sample. There was universal health insurance in 2009 and 2011, so NRCMS should be exogeneity variable in these two years. For robust test, we used sub-sample of 2009 and 2011 to make probit regress as in Model III. Results of all these three models were almost same. Findings of probit models depicted that NRCMS did not reduce catastrophic OOP health expenditure, even in Model III with sub-sample. Per capita household income, age and chronic medical conditions were among factors which reduced probability of catastrophic OOP payments.

To test if the poorest were protected from catastrophic health expenditure by NRCMS, we introduced interaction term between income and NRCMS variables as in Model IV and V in which full sample and sub-sample of 2009 and 2011 were used respectively. We found that this interaction variable was negative significance. It suggested that an increase in household income in the presence of the NRCMS lowered the occurrence of catastrophic payments. Therefore, NRCMS did not provide protection for the poorest as well, even in 2009 and 2011.

Table 6 reported marginal effects of independent variable in both Model II and Model IV, which used the full sample since 2004. The marginal effect of NRCMS was insignificant but ranged from $-0.331 \%$ to $-0.166 \%$. Household income had a significant effect on catastrophic health expenditure; an increase of 1,000 RMB to per capita household income would reduce the occurrence of catastrophic health expenditures by $0.0255 \%-0.0433 \%$.

\section{DisCUSSION}

Using data from CHNS, this paper focused on the impact of the NRCMS on catastrophic health care expenditures for rural residents of China. Our work departed from previous studies in this area as we used a nationally representative source of data for a much longer period, 2004 to 2011. Also, we defined thresholds for catastrophic health care expenditures that varied across income groups. Specifically, for the two lowest income groups (quintiles 1 and 2), the catastrophic health expenditure threshold was set at a fixed absolute amount equivalent to the amount of medical expenditures used to define catastrophic expenditures for the lowest income household in quintile 3 , but for other households it was defined as a fixed proportion (i.e. 25\%) of per capita household income. We argued that even for the poorest set of households, it was unconvincing to identify a household as incurring catastrophic health expenditures if such expenditures were very small and caused the poorest below the poverty line. Certainly, our purpose was not to argue which threshold setting approach was more favorable but to shed light on how differences in the incidence and intensity of catastrophic health care expenditures vary under condition of post-NRCMS reimbursement from 2004 to 2011.

Our results showed that NRCMS did not reduce the incidence of catastrophic health expenditures across the study years, while NRCMS coverage was universal and more reimbursement rate in 2011. It was interesting to note that the incidence $\left(\mathrm{H}_{\text {cat }}\right)$ of catastrophic pre-reimbursement health expenditure was higher in 2011 than in other years. It suggested that total medical expenditures for patients may improve due to generous reimbursement arrangement of NRCMS. This result is consistent with the extensive use of fee-for-service 
reimbursement mechanisms for physicians which encourage the provision of discretionary drug and high-tech care. ${ }^{[3]}$ Another finding was intensity $\left(\mathrm{G}_{c a t}\right)$ of catastrophic health expenditure was still high in 2011 and its difference were small between pre- and post-reimbursement from 2004-2011. Moreover, rural households with higher income were bet- ter protected financially from catastrophic payments than household with the lowest incomes. Both incidence and intensity of catastrophic payment from 2004 to 2011 for the poorest group of household were more substantial than that for households in other income quintiles.

Table 5. Probit model for incidence $\left(\mathrm{H}_{c a t}\right)$ of catastrophic OOP health expenditure

\begin{tabular}{|c|c|c|c|c|c|}
\hline Variables & Model I & Model II & Model III & Model IV & Model V \\
\hline NRCMS & $-0.043(0.559)$ & $-0.018(0.770)$ & $0.102(0.546)$ & $0.108(0.159)$ & $0.352(0.049)$ \\
\hline Age & $0.007(0.006)$ & $0.007(0.006)$ & $0.010(0.017)$ & $0.007(0.006)$ & $0.010(0.019)$ \\
\hline Gender & $-0.062(0.340)$ & $-0.062(0.345)$ & $-0.079(0.412)$ & $-0.061(0.347)$ & $-0.078(0.416)$ \\
\hline Marri & $0.286(0.005)$ & $0.285(0.005)$ & $0.300(0.052)$ & $0.276(0.006)$ & $0.296(0.055)$ \\
\hline Edu & $0.003(0.718)$ & $0.003(0.694)$ & $0.009(0.486)$ & $0.0004(0.962)$ & $0.008(0.514)$ \\
\hline Income & $-0.00002(0.000)$ & $-0.00002(0.000)$ & $-0.00002(0.006)$ & & \\
\hline Income*NRCMS & & & & $-0.00002(0.001)$ & $-0.00002(0.004)$ \\
\hline Hhsize & $-0.022(0.226)$ & $-0.022(0.226)$ & $-0.004(0.875)$ & $-0.016(0.376)$ & $-0.003(0.904)$ \\
\hline Blood & $0.323(0.000)$ & $0.323(0.000)$ & $0.194(0.101)$ & $0.311(0.000)$ & $0.193(0.104)$ \\
\hline Diabetes & $0.472(0.005)$ & $0.472(0.005)$ & $0.413(0.054)$ & $0.465(0.005)$ & $0.417(0.052)$ \\
\hline Myocard & $0.613(0.000)$ & $0.611(0.000)$ & $0.640(0.002)$ & $0.618(0.000)$ & $0.647(0.001)$ \\
\hline Isch & $0.586(0.005)$ & $0.587(0.005)$ & $0.652(0.012)$ & $0.586(0.004)$ & $0.644(0.013)$ \\
\hline _cons & $-2.817(0.000)$ & $-2.825(0.000)$ & $-3.196(0.000)$ & $-2.952(0.000)$ & $-3.415(0.000)$ \\
\hline Obs & 18378 & 18378 & 9028 & 18378 & 9028 \\
\hline Pseudo $\mathrm{R}^{2}$ & - & 0.0652 & 0.0660 & 0.0612 & 0.0676 \\
\hline Wald/LR $\chi^{2}$ & $122.95(0.000)$ & $119.67(0.000)$ & $55.98(0.00)$ & $112.34(0.00)$ & $57.38(0.000)$ \\
\hline Wald test ( $p$ value) & .535 & - & - & - & - \\
\hline
\end{tabular}

Note. $p$-values are in parentheses

Table 6. Marginal effects of Probit model for catastrophic OOP health expenditure

\begin{tabular}{|c|c|c|c|c|}
\hline \multirow[t]{2}{*}{ Variables } & \multicolumn{2}{|l|}{ Model II } & \multicolumn{2}{|c|}{$\begin{array}{c}\text { Model IV (Interaction } \\
\text { model) }\end{array}$} \\
\hline & $\mathbf{d}_{\mathbf{y}} / \mathbf{d}_{\mathbf{x}}$ & $p$-values & $\mathbf{d}_{\mathbf{y}} / \mathbf{d}_{\mathbf{x}}$ & $p$-values \\
\hline NRCMS & -0.000331 & .771 & -0.00166 & .146 \\
\hline Age & 0.000131 & .005 & 0.000134 & .006 \\
\hline Gender & -0.0011 & .343 & -0.00113 & .345 \\
\hline Marri & 0.00403 & .000 & 0.00406 & .000 \\
\hline Edu & 0.0000614 & .694 & 0.00000756 & .962 \\
\hline Income & -0.000000433 & .000 & -0.000000255 & .000 \\
\hline Hhsize & -0.000401 & .225 & -0.0003 & .376 \\
\hline Blood & 0.00816 & .004 & 0.00798 & .005 \\
\hline Diabetes & 0.0152 & .075 & 0.0153 & .076 \\
\hline Myocard & 0.0220 & .102 & 0.0225 & .099 \\
\hline Isch & 0.0234 & .024 & 0.0245 & .022 \\
\hline
\end{tabular}

This study has a number of limitations that warrant review. First, the health expenditure data were based on self-reported medical payments in the four weeks prior to the survey. Such expenditures, even if recalled without bias, may underestimate the underlying incidence and intensity of catastrophic expenditures in one year. Since illness is a random event, we can't annualize these medical expenditures by multiplying it with 12. And the threshold was set as a fixed proportion of annual household income. As a consequence, if annual medical expense data were available, the indicators of catastrophic health expenditures would probably be bigger. Second, our expenditure thresholds were set in a somewhat subjective manner. We didn't directly measure the consumption of necessaries to define the threshold because of such data not available. In spite of these limits, our study demonstrated NRCMS with universal coverage and high reimbursement rates still did not reduce catastrophic OOP health care expenditures in rural China.

In conclusion, this study found that the NRCMS in China has become more universal and more generous in its reimbursement of health expenditures, but these improvements were insufficient to reduce the incidence and intensity of catastrophic health care expenditures. Our finding was consistent with the earlier literature. ${ }^{[4,5]}$ With generous reimbursement arrangements under the NRCMS, total medical expenditures increased, which resulted in patients having higher, not lower OOP catastrophic payments. Moreover, the NRCMS yielded limited protection for households in the lowest income group. 
Our results suggest that policy makers in China should consider how to use the NRCMS to financially protect the poor in rural areas from catastrophic healthcare expenditures.

\section{ACKNOWLEDGEMENTS}

This research is financed by Humanities and Social Sci- ence Foundation of Ministry of Education of China (Grant No: 13YJA790006) and Outstanding Youth and Middle-aged Teachers Training Abroad Program, sponsored by Jiangsu Provincial Education Bureau. We greatly appreciate these supports.

\section{REFERENCES}

[1] O'Donnell O, Van Doorslaer E, Rannan-Eliya R, et al. Catastrophic payments for health care in Asia. Health Economics. 2007; 16: 11591184. PMid: 17311356. http://dx.doi.org/10.1002/hec.120 9

[2] Xu K, Evans D, Kawabata K, et al. Household catastrophic health expenditure: A multicountry analysis. The Lancet. 2003; 362: 111-117. http://dx.doi.org/10.1016/S0140-6736(03) 13861-5

[3] Wagstaff, Gao, Xu L, et al. Extending health insurance to the rural population: An impact evaluation of China's new cooperative medical scheme. Journal of Health Economics. 2009; 28: 1-19. PMid: 19058865. http://dx.doi.org/10.1016/j.jhealeco. 2008.10.007

[4] Winnie Y, William CH. Non-evidence-based policy: How effective is China's new cooperative medical scheme in reducing medical impoverishment? Social Science \& Medicine. 2009; 68: 201-209. PMid: 19019519. http://dx.doi.org/10.1016/j . socscimed. 2008. 09.066

[5] Hongmei YI, Zhang LX, Kim S, et al. Insurance and catastrophic illness: A report on the New Cooperative Medical System in rural China. Health Economics. 2009; 18: S119-S127. PMid: 19551747. http://dx.doi.org/10.1002/hec.1510

[6] Wagstaff A, Doorslaer E. Catastrophe and impoverishment in paying for health care: with applications to Vietnam, 1993-98. Health Economics. 2003; 12: 921-934. PMid: 14601155. http://dx.doi.o $\mathrm{rg} / 10.1002 / \mathrm{hec} .776$

[7] Rama J. Can insurance reduce catastrophic out-of-pocket health expenditure? Working Paper. September, 2008.

[8] Wagstaff A. Measuring financial protection in health. World Bank policy research working paper no. 4554. Washington D.C.: The World Bank. 2008a.

[9] Rama P. Analysing catastrophic OOP health expenditure in India: Concepts, determinants and policy implications. Working Paper. February, 2010.
[10] O’Donnell O, Van Doorslaer E, Rannan-Eliya RP, et al. Who pays for health care in Asia? Journal of Health Economics. 2008; 27(2): 460-475. PMid: 18179832. http://dx.doi.org/10.1016/j.j healeco.2007.08.005

[11] Ranson MK. Reduction of catastrophic health care expenditures by a community-based health insurance scheme in Gujarat, India: Current experiences and challenges. Bulletin of the World Health Organization. 2002; 80: 613-621. PMid: 12219151.

[12] Omar Gala'rraga Sandra G, Aaro'n Salinas-Rodri'guez, Sergio Sesma-Va'zquez. Health insurance for the poor: impact on catastrophic and out-of-pocket health expenditures in Mexico. Europe Journal Health Economics. 2005; 11: 437-447.

[13] Jelena A, Milena P, Wim G. Measuring the catastrophic and impoverishing effect of household health care spending in Serbia. Social Science \& Medicine. 2013; 78: 17-25. PMid: 23267776. http://dx.doi.org/10.1016/j.socscimed.2012.11.014

[14] Sepehri A, Sarma S, Simpson W. Does non-profit health insurance reduce financial burden? Evidence from the Vietnam Living Standards Survey Panel. Health Economics. 2006; 15: 603-616. PMid: 16389632. http://dx.doi.org/10.1002/hec.1080

[15] Cavagnero E, Carrin G, Xu K, et al. Health financing in Argentina: An empirical study of health care expenditure and utilization, Working Paper Series in Innovations in Health Financing, Instituto Nacional de Salud Publica, Mexico. 2006.

[16] Wagstaff A, Magnus L. Can insurance increase financial risk? The curious case of health insurance in China. Journal of Health Economics. 2008; 27; 990-1005. PMid: 18342963. http://dx.doi.o $\mathrm{rg} / 10.1016 / \mathrm{j} \cdot \mathrm{jhealeco} .2008 .02 .002$

[17] Xiaoyan L, Wanchuan L. The New Cooperative Medical Scheme in rural China: does more coverage mean more service and better health? Health Economics. 2009; 18: S25-S46. PMid: 19551752. http://dx.doi.org/10.1002/hec.1501 